American Journal of Pharmaceutical Education 2013; 77 (3) Article 57.

\title{
RESEARCH
}

\section{Pharmacoeconomic Education in Egyptian Schools of Pharmacy}

\author{
Ahmed M. Soliman, MS, BSPharm, ${ }^{a}$ Mustafa Hussein, MS, BSPharm, ${ }^{\text {b }}$ \\ and Abdulla M. Abdulhalim, BSPharm ${ }^{\mathrm{c}}$ \\ ${ }^{a}$ The University of Minnesota College of Pharmacy, Minneapolis, Minnesota \\ ${ }^{\mathrm{b}}$ The University of Tennessee College of Pharmacy, Memphis, Tennessee \\ ${ }^{\mathrm{c}}$ The University of Maryland School of Pharmacy, Baltimore, Maryland \\ Submitted September 5, 2012; accepted October 28, 2012; published April 12, 2013.
}

Objective. To investigate the status of pharmacoeconomics education in Egyptian schools of pharmacy and compile and construct recommendations on how Egypt and similar countries could improve their educational infrastructure in pharmacoeconomics.

Methods. A modified version of a published survey instrument was sent to all schools of pharmacy in Egypt $(n=24)$. The data were assessed to identify associations between offering pharmacoeconomics education and school characteristics.

Results. Usable responses were obtained from 20 schools (response rate: 83\%). Only 7 schools offered pharmacoeconomics education, with a median of 20 teaching hours per semester. Among respondents, 4 schools had instructors with some training in pharmacoeconomics and only 1 school had a faculty member with PhD-level training. Only 4 schools offered graduate-level courses in pharmacoeconomics. Eight additional schools expressed interest in teaching pharmacoeconomics in the near future. Having 1 or more faculty members with training in pharmacoeconomics was significantly associated with offering pharmacoeconomics education $(p=0.03)$.

Conclusions. Pharmacoeconomics education in Egypt is still in its infancy and there exists a unique opportunity for well-trained instructors and researchers to fill this gap. Providing structured pharmacoeconomics education to student pharmacists, researchers, and stakeholders can help countries establish an integrated scientific community that can start applying pharmacoeconomic evidence to healthcare decision-making.

Keywords: pharmacoeconomics, education, Egypt, curriculum

\section{INTRODUCTION}

Pharmacoeconomics is "the scientific discipline that evaluates the clinical, economic, and humanistic aspects of pharmaceutical products, services, and programs, as well as other healthcare interventions to provide healthcare decision makers, providers, and patients with valuable information for optimal outcomes and allocation of healthcare resources."1 As such, formal pharmacoeconomic evidence can potentially inform coverage and reimbursement decisions of various health interventions and technologies, as well as the development of formularies and clinical practice guidelines. ${ }^{2}$ This is especially

Corresponding Author: Ahmed M. Soliman, BSPharm, MS, Doctoral Dissertation Fellow, Social and Administrative Pharmacy Graduate Program, Department of Pharmaceutical Care and Health Systems, College of Pharmacy, University of Minnesota, 7-164 Weaver-Densford Hall, 308 Harvard St SE, Minneapolis, MN 55455. Tel: 612-353-7804. E-mail:

solim008@umn.edu important in lower income countries that face more serious constraints on the allocation of their scarce healthcare resources.

Using pharmacoeconomic evidence in developing national formularies and essential medicines policies in developing nations can help bring a better value for the investment in pharmaceuticals. Further, the use of pharmacoeconomics in broader healthcare decision making in developing countries may help to optimize access, cost, and quality of care for the populations of these nations. ${ }^{3,4}$ However, as Singer explains, 3 components ought to be in place before the full potential of pharmacoeconomics can be realized: individuals capable of conducting the analyses; a receptive and informed audience of policymakers; and a body of relevant methodology and guidelines. ${ }^{5}$ Thus, it is imperative for developing countries to build an educational infrastructure of analysts and experts in pharmacoeconomics and to promote the education of pharmacoeconomics at the payer, provider, and researcher levels, each according to their needs and tasks. 


\section{American Journal of Pharmaceutical Education 2013; 77 (3) Article 57.}

Pharmacoeconomics education has flourished in the developed world. The number of US pharmacy colleges and schools teaching pharmacoeconomics at the professional level increased from $80 \%$ in 1997 to $92 \%$ in 2007 , and the colleges and schools that did not offer pharmacoeconomics courses were either new or looking for instructors. ${ }^{6,7}$ Internationally, the percentage of pharmacy colleges and schools offering pharmacoeconomic education increased from $41 \%$ in 1997 to $52 \%$ in $2004 .{ }^{8,9}$ In this international survey, usable responses were recovered from only 4 Middle Eastern countries: Jordan, Lebanon, the Palestinian Territory, and Turkey.

Egypt is a developing country classified as a lower middle-income country by the World Bank. ${ }^{10}$ The performance of the health system in Egypt was ranked 63rd among 191 countries in the 2000 World Health Report by the World Health Organization ${ }^{11}$ using a composite measure of the overall health system performance, and was ranked 105th among 197 countries in 2004, based on Egypt's disability-adjusted life expectancy. ${ }^{12}$ According to the country's national health accounts in 2007-2008, Egypt's total health expenditure was only $4.8 \%$ of the gross domestic product, which is 1 of the lowest among all countries in the Middle East. ${ }^{13}$ Sixty percent of the country's total health expenditure is paid for by households, which is the highest percentage among all middle-income countries; $35 \%$ is financed by the Egyptian Ministry of Health. ${ }^{13}$ Spending on pharmaceuticals makes up about $26 \%$ of total healthcare expenditure in Egypt, and about a third of households' out-of-pocket healthcare spending. ${ }^{13}$

Egypt has the largest number of pharmacy schools among countries in the Middle East (currently 24), and the number of pharmacists per 100,000 people is $1.7,{ }^{14}$ making Egypt the major exporter of pharmacy graduates in the Middle East. ${ }^{15}$ Over $75 \%$ of all students admitted to pharmacy programs in 13 Middle Eastern countries obtain their pharmacy education in Egypt.

We explored the current status of undergraduate (professional) and graduate pharmacoeconomic education in Egyptian schools of pharmacy. To the best of our knowledge, this study is one of the first attempts to comprehensively assess the extent of pharmacoeconomics education in a Middle Eastern country. We also sought to contribute to the literature on capacity building in pharmacoeconomic education by consolidating relevant recommendations from the literature for Egypt and similar countries on how to strengthen their educational infrastructure in pharmacoeconomics.

\section{METHODS}

The survey instrument developed by Rascati and colleagues ${ }^{7}$ was adapted and modified into a 15 -item survey instrument to suit our research purpose. The list of schools of pharmacy in Egypt was obtained from the Egyptian Syndicate of Pharmacists, which maintains a list of universities that offer a pharmacy degree in the country. E-mail addresses and other contact information for the school deans and department chairs were obtained from each school's Web site. We presumed that the departments that may be offering pharmacoeconomics courses were clinical pharmacy, pharmacy practice, and drug technology. For every pharmacy school in Egypt, the survey instrument along with a cover letter explaining the purpose of the survey and providing a definition of pharmacoeconomics was sent by e-mail to the department head under which pharmacoeconomics was presumed to be offered, or to a full-time faculty member in the same department when it was not possible to reach the chair. To increase the response rate, a follow-up e-mail was sent to nonresponders 3 weeks after the first e-mail, and then the survey instrument was mailed to them. Finally, we attempted to contact the remaining nonresponders in person with the help of members of Egypt's regional chapter of the International Society for Pharmacoeconomics and Outcomes Research (ISPOR). The first round of survey administration was conducted in October 2011. In an effort to maximize the survey response rate, in August 2012, we conducted a second round of survey administration in which we contacted only schools that did not respond in the first round.

Descriptive statistics were computed for the usable survey responses that were received. For a school to be counted as offering pharmacoeconomics education, an elective or required course or part of a course had to be reported that explicitly covered some of the topical areas within pharmacoeconomics. This criterion was based on the premise that if a school was providing its students with an educational opportunity in pharmacoeconomics, then it was indeed offering pharmacoeconomics. This criterion was used in previous research on the status of pharmacoeconomics education in the United States and elsewhere. ${ }^{6,7,16}$

The Fisher exact test was applied to the respondents' data to investigate the association between the proportion of schools offering pharmacoeconomics and certain school characteristics, namely, type of funding source (private vs. public), whether a school was located within the Greater Cairo metropolitan area, and whether a school had faculty members trained in pharmacoeconomics. The significance level was set at 5\%. Data collection and analysis were conducted using Microsoft Excel 2007.

\section{RESULTS}

As of October 2011, Egypt had 24 schools of pharmacy, with 2 campuses offering pharmacy education 


\section{American Journal of Pharmaceutical Education 2013; 77 (3) Article 57.}

under the auspices of the Faculty of Pharmacy of AlAzhar University. The bachelor of science in pharmacy (BS Pharm) degree remains the first professional degree required to practice pharmacy in Egypt, and is awarded after completion of a 5-year professional program. A summary of survey results is provided in Table 1, and the characteristics of all pharmacy schools in Egypt are listed along with whether they offered pharmacoeconomics education in Table 2.

The survey instrument was sent to representatives at all 24 schools of pharmacy in Egypt, and we received usable responses from 20 (83\% response rate). Among the respondents, as delineated in Table 2 and Table 3, only $7(35 \%)$ schools offered pharmacoeconomics education at the time the survey was completed. Pharmacoeconomics was taught over a median of 20 teaching hours per semester (range: 2-45 hours), which reflects that some schools offered a dedicated course on pharmacoeconomics and related topics (eg, pharmacy administration and pharmaceutical marketing) while others offered only brief coverage of pharmacoeconomics as a part of another course (eg, clinical and hospital pharmacy). The median class size at each school was 400 students (range: 1501300 students). Courses that were entirely dedicated to teaching pharmacoeconomics were a required, integral part of the curriculum. At the graduate level, only 4 schools offered pharmacoeconomics education (Table 3). Those 4 schools had actively enrolled master's degree students pursuing graduate degrees with a focus on pharmacoeconomics. Faculty responsible for teaching pharmacoeconomics came from departments of pharmacology, pharmacy practice, or drug technology (Table 3). None of the schools had a pharmacy administration/pharmacoeconomics

Table 1. Summary of Findings From a Survey of Egyptian Pharmacy Schools Regarding Incorporation of Pharmacoeconomics Education Within the Curriculum

\begin{tabular}{lc}
\hline & No. (\%) \\
\hline Schools surveyed & $24(100)$ \\
Respondents & $20(83)$ \\
$\begin{array}{l}\text { Schools offering pharmacoeconomics } \\
\text { Schools planning to offer pharmaco-economics }\end{array}$ & $7(35)$ \\
$\quad$ in the next 2-4 years & $15(75)$ \\
$\begin{array}{l}\text { Schools having faculty trained in } \\
\text { pharmacoeconomics }\end{array}$ & $5^{\mathrm{a}}(25)$ \\
$\begin{array}{l}\text { Schools offering pharmacoeconomics } \\
\text { at the graduate level }\end{array}$ & $4(20)^{\mathrm{b}}$ \\
\hline
\end{tabular}

$\overline{{ }^{a} \text { Cairo University, although not offering pharmacoeconomics at the }}$ time of survey administration, is the only school in Egypt with a faculty with formal $\mathrm{PhD}$ training in pharmacoeconomics.

${ }^{\mathrm{b}}$ Of the 7 schools offering pharmacoeconomics education, 4 (57\%) also offered it at the graduate level. department. Five of the 7 schools that offered pharmacoeconomics had instructors with some training in pharmacoeconomics. The pharmacy school at Cairo University appears to be the only school that has a faculty member with formal $\mathrm{PhD}$ training in pharmacoeconomics. Nonetheless, this school reported that pharmacoeconomics is not currently offered in its curriculum.

The main texts used in pharmacoeconomics courses were Essentials of Pharmacoeconomics by Karen Rascati ${ }^{17}$ and Pharmacoeconomics by Tom Walley and co-authors. ${ }^{18}$ The pharmacoeconomics topics most commonly taught (Table 4) included types of health care costs and outcomes within the economic, clinical, and humanistic outcomes model; potential applications of pharmacoeconomics in various settings; assessment of health-related quality of life; basics of decision analysis; and pharmacoepidemiology. Types of economic evaluation (eg, cost-utility analysis and cost-benefit analysis) were emphasized at some schools as well.

In addition to the 7 schools that taught pharmacoeconomics either in a separate course or within other courses, 8 other schools expressed interest in offering a pharmacoeconomic course in the near future (2-4 years).

All the schools that responded to the question of how they valued the importance of pharmacoeconomics education expressed their appreciation of the significant role this field can play in optimizing healthcare decisionmaking and resource allocation.

Among respondents, 10 schools were private and 10 were located within the Greater Cairo metropolitan area. There was a significant association between offering pharmacoeconomics and having faculty members trained in pharmacoeconomics $(p=0.031)$. A school's funding source or its location were not significantly associated with whether it offered a pharmacoeconomics course $(p=0.35)$.

\section{DISCUSSION}

Pharmacoeconomic education in Egypt is still in its infancy and only a small number of schools are teaching pharmacoeconomics at the undergraduate and graduate levels. Another key finding from this study was the limited expertise that Egyptian schools of pharmacy have in this field. Formal training of instructors in pharmacoeconomics was limited to vocational courses except at Cairo University. Nevertheless, $75 \%$ of responding schools expressed interest in offering pharmacoeconomics within the professional curriculum, which indicates a need for more faculty members trained in this area to teach these courses.

Historically, pharmaceutical education in Egypt was mostly limited to basic biomedical and pharmaceutical 
American Journal of Pharmaceutical Education 2013; 77 (3) Article 57.

Table 2. Pharmacy Schools in Egypt: Characteristics and Status of Pharmacoeconomics Education

\begin{tabular}{|c|c|c|c|c|c|c|}
\hline School of Pharmacy & $\begin{array}{c}\text { Average } \\
\text { Class Size }^{\mathrm{a}}\end{array}$ & $\begin{array}{l}\text { Funding } \\
\text { Source }^{\mathrm{a}}\end{array}$ & $\begin{array}{c}\text { Location } \\
\text { (City) }\end{array}$ & $\begin{array}{c}\text { Year } \\
\text { Established }^{\mathrm{a}}\end{array}$ & $\begin{array}{c}\text { Offering } \\
\text { Pharmaco- } \\
\text { Economics } \\
\text { Courses? }\end{array}$ & $\begin{array}{c}\text { Planning to Offer } \\
\text { Pharmaco-Economics } \\
\text { in the Next 2-4 Years? }\end{array}$ \\
\hline Ahram Canadian University & 210 & Private & Giza & 2004 & Yes & Yes \\
\hline Ain Shams University & 600 & Public & Cairo & 1995 & Yes & Yes \\
\hline $\begin{array}{l}\text { Al-Azhar University- } \\
\text { Cairo/Assiut }\end{array}$ & $700 / 383$ & Public & Cairo/Assiut & $1965 / 1993$ & No & Yes \\
\hline Alexandria University & 1500 & Public & Alexandria & 1955 & Yes & Yes \\
\hline Assiut University & 900 & Public & Assiut & 1957 & No & No \\
\hline Beni Swef University & 360 & Public & Beni Swef & 1994 & No & Yes \\
\hline Cairo University & 1500 & Public & Cairo & 1925 & No & Yes \\
\hline Egyptian Russian University & 280 & Private & Cairo & 2006 & Yes & Yes \\
\hline Future University in Egypt & 300 & Private & Cairo & 2006 & Yes & Yes \\
\hline German University in Cairo & 450 & Private & Cairo & 2003 & Yes & Yes \\
\hline Helwan University & 400 & Public & Helwan & 1994 & No & Yes \\
\hline Mansoura University & 1200 & Public & Mansoura & 1972 & $N R$ & $N R$ \\
\hline Minia University & 330 & Public & Minia & 1995 & No & No \\
\hline Misr International University & 450 & Private & Cairo & 1997 & No & Yes \\
\hline $\begin{array}{l}\text { Misr University for Science } \\
\text { \& Technology }\end{array}$ & 500 & Private & Giza & 1997 & No & No \\
\hline $\begin{array}{l}\text { Modern Sciences \& Arts } \\
\text { University }\end{array}$ & 300 & Private & Giza & 2003 & No & Yes \\
\hline $\begin{array}{l}\text { Modern University for } \\
\text { Technology \& } \\
\text { Information }\end{array}$ & 200 & Private & Cairo & 2010 & $N R$ & $N R$ \\
\hline Nahda University & 300 & Private & Beni Swef & 2007 & No & Yes \\
\hline October 6th University & 850 & Private & Cairo & 1997 & $N R$ & $N R$ \\
\hline Pharos University & 350 & Private & Alexandria & 2006 & No & Yes \\
\hline Sinai University & 300 & Private & Arish & 2006 & Yes & Yes \\
\hline Suez Canal University & 250 & Public & Ismailia & 1993 & No & No \\
\hline Tanta University & 1200 & Public & Tanta & 1973 & $N R$ & $N R$ \\
\hline Zagazig University & 1200 & Public & Zagazig & 1976 & No & No \\
\hline
\end{tabular}

${ }^{a}$ Data on funding source and year of establishment were obtained from the Web sites of each of the listed schools. Data on average class size were obtained from the responses of schools to the survey, and, for non-respondents, from the respective school's Office of Student Affairs through a personal communication with a school's academic/administrative official. NR: No response

sciences, with some individual initiatives to teach and implement relatively newer fields of study like pharmacoeconomics and clinical pharmacy. We believe that the adoption of pharmacoeconomics in Egyptian schools of pharmacy has lagged behind for many reasons. First, the lack of awareness about the existence and importance of pharmacoeconomics on the side of curriculum decision makers (deans and department chairs) poses a barrier to adopting pharmacoeconomics into the curriculum. Second, the lack of experts in this field who reside in Egypt makes it more difficult to recruit instructors who can teach this subject in the pharmacy curriculum. Third, as with any emerging area of education, efforts and resources must be expended to build sound foundations. However, in most cases, the Egyptian higher education sector lacks access to the financial resources and appropriate planning needed.

Over the last 2 decades, Egypt has seen a dramatic change in the funding landscape of its universities. Starting in the late 1990s, many privately funded schools of pharmacy have been established. All private universities in Egypt are mandated to follow the same process of legal recognition and approval by the Ministry of Higher Education and the Supreme Council of Universities as state universities do, on the basis of the Presidential Decrees issued for the establishment of those institutions. ${ }^{15,19}$ One interesting finding from this study is that the majority of schools of pharmacy offering pharmacoeconomics education were private schools ( 5 of the 7 schools, see Table 2 and Table 3). We believe that this observation can be 


\section{American Journal of Pharmaceutical Education 2013; 77 (3) Article 57.}

Table 3. Characteristics of Schools Offering Pharmacoeconomics Education in Egypt

\begin{tabular}{lccccc}
\hline & $\begin{array}{c}\text { Teaching Hours } \\
\text { (per semester) }\end{array}$ & $\begin{array}{c}\text { Pharmaco- } \\
\text { economics } \\
\text { Class Size }^{\mathbf{a}}\end{array}$ & $\begin{array}{c}\text { Offering Pharmaco- } \\
\text { economics at } \\
\text { School of Pharmacy }\end{array}$ & $\begin{array}{c}\text { Academic Department } \\
\text { Teaching }\end{array}$ & $\begin{array}{c}\text { Faculty Trained } \\
\text { in Pharmaco- } \\
\text { economics? }^{\mathbf{b}}\end{array}$ \\
\hline Ahram Canadian University & 45 & 400 & No & Pharmacy Practice & Yes (MBA) \\
Ain Shams University & 45 & 600 & Yes & Drug Technology & Yes (Courses) \\
Egyptian Russian University & 32 & 280 & Yes & Pharmacology & No \\
German University in Cairo & 18 & 400 & No & Pharmacology & Yes (Courses) \\
Alexandria University & 2 & 1300 & Yes & Pharmaceutics & No \\
Future University & 10 & 175 & No & Pharmacy Practice & No \\
Sinai University & 20 & 150 & Yes & Pharmacy Practice & Yes (Diploma) \\
Median & 20 & 400 & & & \\
Average & 24.6 & 472 & & & \\
\hline
\end{tabular}

${ }^{a}$ Reported numbers reflect the class size at the professional level only.

${ }^{\mathrm{b}}$ Cairo University, not listed, is the only school in Egypt with a faculty with formal $\mathrm{PhD}$ training in pharmacoeconomics.

attributed to the disparity in resource availability between private and public universities. Typically, pharmacy schools that are funded through private sources have more opportunities to expand and teach newer fields compared to public universities.

Although the literature search did not recover any formal studies that document the status of pharmacoeconomics education in a Middle Eastern country, there are a few individually reported cases. In Saudi Arabia, several initiatives have been undertaken to develop internationally recognized pharmacy education and to receive international accreditation, such as from the Canadian Council for Accreditation of Pharmacy Programs (CCAPP), especially at schools that have taken the lead in pharmacy education in that country. ${ }^{20}$ International Pharmacoeconomics courses are offered in both classroom and experiential settings during the doctor of pharmacy (PharmD) degree at King Saud University. ${ }^{20}$ In terms of research, apparently there is an ongoing agenda in Saudi Arabia for the adoption of pharmacoeconomic analysis in formulary management and healthcare decision making in their health system, especially in the National Guard and similar government-funded hospitals. ${ }^{21,22}$ Nwokeji and Rascati's 2004 survey of pharmacoeconomic education outside of the United States documented that pharmacoeconomics was offered at the professional level in only 1 school in the Middle East, in Lebanon. ${ }^{8}$ The Lebanese American University, which appears to be the only school of pharmacy in Lebanon, lists pharmacoeconomics in its pharmacy curriculum. ${ }^{23}$ Also, Qatar University, which has the first school of pharmacy in Qatar that is accredited by the CCAPP, lists pharmacoeconomics courses in the pharmacy curriculum ${ }^{24}$ and has hired faculty members who are pharmacoeconomics experts to teach and conduct research. ${ }^{25}$ The University of Jordan's Web site indicates that pharmacoeconomics courses are offered as part of the curriculum for their BSPharm and PharmD degrees. ${ }^{26}$

In a wider international context, the extent of pharmacoeconomic education in Egyptian schools of pharmacy appears to be comparable to that reported by other schools outside of the United States, especially when taking into account that the most recent report on the international status was in $2005 .^{8}$ Fifty-two percent of responding schools ( 47 schools in 28 countries) in Nwokeji and Rascati's international study indicated that they offered some pharmacoeconomics education (19 schools from Europe, 10 from Asia, 7 from North America [Canada and Mexico], and 6 from Oceania, and the rest from elsewhere). ${ }^{8}$ Nine (19\%) of these schools offered pharmacoeconomics at the bachelor's degree level only, $16(34 \%)$ at the graduate level only, and $22(47 \%)$ offered education at both levels. ${ }^{8}$ In our study, 7 (35\%) Egyptian schools

Table 4. Topics Most Commonly Taught in Pharmacoeconomics Courses

\begin{tabular}{ll}
\hline Topic & $\begin{array}{c}\text { Schools Teaching, } \\
\text { No. \% }\end{array}$ \\
\hline $\begin{array}{l}\text { Types of health care costs: Direct, } \\
\text { Indirect, etc }\end{array}$ & $7(100)$ \\
$\begin{array}{l}\text { Applications of pharmacoeconomics } \\
\text { (Industry, Hospitals, Formulary, etc) }\end{array}$ & $7(100)$ \\
Health-related quality of life & $6(86)$ \\
$\begin{array}{l}\text { Decision analysis } \\
\text { Epidemiology / Pharamcoepidemiology }\end{array}$ & $5(71)$ \\
Pharmaceutical Policy & $5(71)$ \\
Types of pharmacoeconomic analysis & $4(57)$ \\
$\quad$ (eg CEA, CBA, CUA, CMA, BIA, & $3(43)$ \\
$\quad$ Cost of Illness) & \\
\hline Abbreviations: CEA = Cost-Effectiveness Analysis; CBA = Cost- \\
Benefit Analysis; CUA = Cost-Utility Analysis; CMA = Cost \\
Minimization Analysis; BIA = Budget Impact Analysis
\end{tabular}




\section{American Journal of Pharmaceutical Education 2013; 77 (3) Article 57.}

offered some pharmacoeconomic education, $3(43 \%)$ at the bachelor's degree level and $4(57 \%)$ at the bachelor's and graduate levels (Table 1). Qualitatively, several schools expressed interest in offering pharmacoeconomics courses, a few school officials requested information that would help their institutions establish a pharmacoeconomics program, while others acknowledged that pharmacoeconomics is a relatively new field that is important to the planning of pharmaceutical services provision in their countries. ${ }^{8}$

This study is the first attempt to report on the status of pharmacoeconomics education in Egypt by conducting a comprehensive survey of all 24 schools of pharmacy in the country using an updated survey instrument. We also used multiple methods to maximize the response rate. The response rate achieved in our study $(83 \%)$ minimizes the likelihood of nonresponse bias. ${ }^{27}$

Because this is the first report on pharmacoeconomic education in Egypt, a follow-up study should be performed in the next 2 to 3 years. Given that many schools expressed their interest in teaching pharmacoeconomics in the near future, it would be useful to assess the change in the extent of pharmacoeconomic education in Egypt over time, especially at the graduate level. Previous studies have shown that the rate of uptake of pharmacoeconomics as a part of pharmacy curriculum has generally increased over the last decade. Testing for a similar trend in Egypt should be a future goal for research in this area.

One limitation of our study is that because pharmacoeconomics may be considered a sub-discipline of both pharmacy and economics, we could be missing courses taught in the departments of economics throughout Egypt. By definition, however, our exploration of the status of pharmacoeconomics education was limited to Egyptian schools of pharmacy. Nonetheless, anecdotal evidence and a comprehensive Internet survey we conducted on the electronically published curricula (including those published in Arabic) of the schools of commerce, economics, and political sciences support the hypothesis that teaching pharmacoeconomics in those departments is highly unlikely. Further, to our knowledge, health economics, the parent discipline of pharmacoeconomics, is not traditionally an area of interest within the curricula of these schools, which are more focused on business and related subdisciplines of economics. Another potential limitation is that we did not attempt to investigate the details of graduate-level pharmacoeconomics education in the responding schools. Our goal was primarily to document offering pharmacoeconomics education at any level, with a focus on the professional curriculum. Nevertheless, our findings show that graduate education in pharmacoeconomics is still in its beginnings, with no formally structured programs in social and administrative pharmacy or pharmacoeconomics, making it difficult to collect data on the particulars of graduate coursework in pharmacoeconomics in Egypt.

\section{Recommendations}

We offer the following recommendations, consolidated from existing literature, on how to best proceed in building a strong foundation for pharmacoeconomics education in Egypt and similar low- and middle-income countries:

1. Use well-established standardized learning outcomes to guide course directors. Standardizedlearning outcomes and optimal levels of education for different types of learners of pharmacoeconomics have been established by ISPOR taskforces. $^{28}$ The review by Rascati and colleagues in 2004 provides an appealing summary of those learning outcomes, with the purpose of helping teachers and learners understand their educational needs and assess the ability of the curricula to meet them. ${ }^{16}$ Also, the American College of Clinical Pharmacy, in collaboration with ISPOR, standardized the learning outcomes of pharmacoeconomics fellowships for pharmacy residents. ${ }^{29}$ These standards can serve as guidelines for course directors in Egypt and other countries that plan to start offering pharmacoeconomics courses of high quality.

2. Raise awareness about pharmacoeconomics among various stakeholders. This can be accomplished through continuing education activities, seminars, and short courses for health policy makers, physicians, pharmacists, and other professionals expected to be involved in decisionmaking processes, which require a good understanding of pharmacoeconomic concepts and the scope of their application.

3. Encourage formal pharmacoeconomics education and training. Healthcare professionals in training, such as student pharmacists and physicians, should have formal pharmacoeconomics education as a part of their required coursework and experiential training. The goal would be to develop their ability to apply pharmacoeconomic knowledge to critically evaluate economic evidence when making decisions in their practice. For other individuals interested in developing a deeper level of understanding of pharmacoeconomics, graduate-level training should be another available option. Building a homegrown base of pharmacoeconomics experts could only be accomplished through formal degrees (eg, doctor 


\section{American Journal of Pharmaceutical Education 2013; 77 (3) Article 57.}

of philosophy) and research fellowships, where students learn how to conceptualize pharmacoeconomics at a more advanced level, synthesize new clinical and economic knowledge, develop new methodologies, and assimilate the multidisciplinary knowledge of pharmacoeconomics from its parent disciplines. ${ }^{16}$

These 3 pathways should be pursued in parallel to maximize the overall educational benefit in order to establish the nucleus of a pharmacoeconomics scientific community in Egypt. In the initial years of development, these 3 pathways may have to be followed by bringing foreign experts into the country for teaching and consultation; by encouraging and funding interested students to attend international meetings, seminars, and short courses; and by offering academic scholarships for pursuing graduate education in countries where pharmacoeconomics is a wellestablished discipline.

4. Characterize and understand the structure of the Egyptian health care system and its regulatory atmosphere. Although promoting pharmacoeconomics education appears to give a good return on investment with a great potential to help revolutionize Egypt's health system by improving its economic efficiency, improvement in resource allocation by itself might not be enough to strengthen and transform health systems. The appropriate use of credible pharmacoeconomic evidence can help strengthen health systems only when essential structural and regulatory policy measures are being implemented, along with continuous improvement in transparency and accountability within national pharmacy systems. ${ }^{30}$ Healthcare-related decisionmaking in developing countries cannot blindly adopt pharmacoeconomic guidelines developed for health systems in industrialized countries. ${ }^{31}$ Some of the fundamental barriers to such a practice may include variation in disease burden; epidemiology; the potentially different values and expectations stakeholders place on health services, which directly influence their willingness to pay and acceptability thresholds; and the degree to which there is a defined regulatory structure for the healthcare system, in terms of insurance coverage, payers involved, payment and reimbursement mechanisms, and pricing practices. $^{3,32}$ Specific guidelines pertinent to a developing nation thus need to be conceptualized and developed in the light of the different aspects of its health system's capacity, available resources, societal needs and priorities, and the structure through which pharmacoeconomics can be used to inform decision making.

\section{CONCLUSION}

There is a great deficit in the availability of pharmacoeconomics courses in pharmacy schools in Egypt at both the undergraduate and graduate levels. Findings from this study suggest that the lack of expertise in this subject area among faculty members is key to the deficit. A unique opportunity exists for well-trained individuals to fill this gap. Providing pharmacoeconomic education to pharmacy students is especially important in an era when evidence-based healthcare decision making may be considered one of the priorities for the Egyptian government.

\section{ACKNOWLEDGMENTS}

The authors thank Professor C. Daniel Mullins for reviewing and providing feedback on earlier versions of the manuscript. The authors would also like to thank members of Egypt's regional ISPOR chapter and Ahmed El-Wakeel of the Faculty of Pharmacy at Sinai University for help with survey administration and data collection. No funding was obtained to complete this study. The authors had no conflicts of interest. An earlier version of this study was presented as a poster at the 17th Annual International Meeting of ISPOR in Washington, DC, in June 2012.

\section{REFERENCES}

1. Berger ML, Bingefors K, Hedblom EC, Pashos CL, Torrance GW. Health Care Cost, Quality, and Outcomes: ISPOR Book of Terms. Lawrenceville, NJ: ISPOR; 2003.

2. The International Society for Pharmacoeconomics and Outcomes Research. Pharmacoeconomics (Issues). http://www.ispor.org/ terminology/default.asp. Accessed March 30, 2012.

3. Villa LA, Skrepnek GH. Pharmacoeconomics and developing nations. Pharm Policy Law. 2012;14:17-25.

4. Singer ME. Developing nations special issue. Pharmacoeconomics. 2009;27(11):887-889.

5. Singer ME. Cost-effectiveness analysis, developing nations left behind. Pharmacoeconomics. 2008;26(5):359-361.

6. Reddy M, Rascati KL, Wahawisan J, Rascati M.

Pharmacoeconomic education in US colleges and schools of pharmacy: an update. Am J Pharm Educ. 2008;72(4):Article 51.

7. Rascati KL, Conner TM, Draugalis JR. Pharmacoeconomic education in US schools of pharmacy. Am J Pharm Educ. 1998; 62(3):167-169.

8. Nwokeji ED, Rascati KL. Pharmacoeconomic education in colleges of pharmacy outside of the United States. Am J Pharm Educ. 2005;69(3):348-355.

9. Rascati KL, Draugalis JT, Conner T. Pharmacoeconomic education in schools of pharmacy. In: Salek S, ed.

Pharmacoeconomics and Outcome Assessment: A Global Issue. Haslemere, UK: University of Wales, Cardiff; 1999:25-32. 


\section{American Journal of Pharmaceutical Education 2013; 77 (3) Article 57.}

10. The World Bank. How we classify countries. http://go.worldbank. org/AJGKUS0E80. Accessed March 31, 2012.

11. World Health Organization (WHO). World health report 2000. Geneva, Switzerland: World Health Organization (WHO); 2000. 12. World Health Organization (WHO). The global burden of disease 2004 update. Geneva, Switzerland: World Health Organization (WHO); 2008.

13. Ministry of Health, Egypt, and Health Systems 20/20. National Health Accounts 2007/2008: Egypt. Bethesda, MD: Health Systems 20/20 Project, Abt Associates Inc.; 2010.

14. World Health Organization (WHO). World health statistics 2011. Geneva, Switzerland: World Health Organization; 2011.

15. Kheir N, Zaidan M, Younes H, Hajj ME, Wilbur K, Jewesson PJ. Pharmacy education and practice in 13 Middle Eastern countries. Am J Pharm Educ. 2008;72(6):Article 133.

16. Rascati KL, Drummond MF, Annemans L, Davey PG. Education in pharmacoeconomics: an international multidisciplinary view.

Pharmacoeconomics. 2004;22(3):139-147.

17. Rascati K. Essentials of Pharmacoeconomics. 1st ed. Philadelphia, PA: Lippincott Williams \& Wilkins; 2008.

18. Walley T, Haycox A, Boland A. Pharmacoeconomics. Edinburgh, UK: Churchill Livingstone; 2004.

19. Minister's of Higher Education Bureau. A Guide on faculties and institutes of higher education in the arab republic of egypt (p. 436-

589). http://www.egy-mhe.gov.eg/english/guide2008.pdf. Accessed October 1, 2012.

20. Asiri YA. Emerging frontiers of pharmacy education in Saudi Arabia: the metamorphosis in the last fifty years. Saudi Pharm J. 2011;19(1):1-8.

21. Alsultan MS. The role of pharmacoeconomics in formulary decision making in different hospitals in Riyadh, Saudi Arabia. Saudi Pharm J. 2011;19(1):51-56.

22. Al-Jazairi AS, Al-Qadheeb NS, Ajlan A. Pharmacoeconomic analysis in Saudi Arabia: an overdue agenda item for action. Ann Saudi Med. 2011;31(4):335-341.

23. Lebanese American University School of Pharmacy. Full pharmacy curriculum. http://pharmacy.lau.edu.lb/programs/ curriculum/ataglance.php. Accessed April 1, 2012.
24. Qatar University College of Pharmacy. Baccalaureate of science in pharmacy degree, curricular map. http://www.qu.edu. qa/pharmacy/program/documents/11AYFS_CPH_BSc_PD_ Curriculum_Map_Oct_10_2011_SK_PJ_signed.pdf. Accessed April 1, 2012.

25. Qatar University College of Pharmacy. Faculty Bios and Research Interests, Clinical Pharmacy and Practice Section. http:// www.qu.edu.qa/pharmacy/research/faculty_bio.php. Accessed April $1,2012$.

26. The University of Jordan Faculty of Pharmacy. Programs: Bachelor of Science in Pharmacy. http://pharmacy.ju.edu.jo/Lists/ OurPrograms/Attachments/9/BSc\%20Pharmacy.pdf. Accessed March 25, 2013.

27. Draugalis JR, Plaza CM. Best practices for survey research reports revisited: implications of target population, probability sampling, and response rate. Am J Pharm Educ. 2009;73(8):Article 142.

28. The International Society for Pharmacoeconomics and Outcomes Research. Pharmacoeconomic \& outcomes research learning outcomes. http://www.ispor.org/education/learning_outcomes.asp. Accessed September 4, 2012.

29. Kane-Gill S, Reddy P, Gupta SR, Bakst AW. Guidelines for pharmacoeconomic and outcomes research fellowship training programs: joint guidelines from the American College of Clinical Pharmacy and the International Society of Pharmacoeconomics and Outcomes Research. Pharmacotherapy. 2008;28(12):15521552.

30. Babar ZU, Scahill SL. Is there a role for pharmacoeconomics in developing countries? Author's reply. Pharmacoeconomics. 2011; 29(5):436-437.

31. Oortwijn W, Mathijssen J, Banta D. The role of health technology assessment on pharmaceutical reimbursement in selected middle-income countries. Health Policy. 2010;95(2-3): 174-184.

32. Shillcutt SD Walker DG, Goodman CA, Mills AJ. Cost effectiveness in low- and middle-income countries: a review of the debates surrounding decision rules. Pharmacoeconomics. 2009;27(11):903-917. 